\title{
GÊNERO E O BNDES: SERIA MAIS UM CASO DE MACHISMO ESTRUTURAL?
}

\author{
Glória Estevinho $^{1}$
}

\begin{abstract}
Resumo: Maria Silvia Bastos Marques é uma renomada economista da FGV e conhecida pelo seu pioneirismo em assumir cargos importantes em companhias de proeminência Nacional. Foi a primeira e única mulher a presidir a Companhia Siderúrgica Nacional (CSN) e o BNDES (Banco Nacional de Desenvolvimento Econômico e Social). Este artigo, pretende dirigir um olhar às questões de gênero em ambientes de predominância masculina. A partir da observação do quadro dos presidentes do BNDES, constatou-se uma sucessão de homens, na ocupação do cargo, desde a fundação até o ano de 2016/2017, quando o ciclo se rompe com a indicação feminina. Nossa proposta é de um levantamento biográfico da trajetória da única mulher a compor esse quadro, fazendo reflexões quanto ao feminismo e estabelecendo um diálogo com a existência de um machismo estrutural. Como referência teremos por base os estudos realizados pelo NEP (Núcleo de Estudos Paranaenses), avaliando as condições da existência de uma estrutura machista de longa duração, ao mesmo tempo, em que, denota-se a importância da mulher nos estudos de genealogia. Essa estrutura está presente em determinados ambientes como na política, nas instituições e na sociedade como um todo. Propomos apresentar dados que contribuam com a genealogia do poder, levando em conta as questões de gênero bem como seus capitais culturais, sociais e políticos em relação ao cargo. Nossos esforços são voltados para compreender que capitais agregam e permitem romper barreiras em algum campo dentro da estrutura social observando sua atuação. Seria uma linhagem ligada ao parentesco, ou a construção dos capitais sociais, cultural e profissional que proporcionam leitura, sobre tais condições de acesso, a um ambiente tradicionalmente ocupado por homens? O que embasa nossos questionamentos são as produções realizadas pelo NEP sobre família e parentesco, bem como o entendimento sobre a importância da mulher na constituição do espaço social. O método utilizado será análise biográfica. Esse estudo faz parte de pesquisa em desenvolvimento no programa de pós-graduação (mestrado), onde estão sendo levantadas as biografias dos presidentes do BNDES. Esse levantamento será analisado pela prosopografia, para compreensão do perfil geral dos presidentes e de que maneira tal composição influência nas diretrizes adotadas pelo banco. Portanto, o problema que se coloca é a identificação do perfil da mulher para assumir o cargo máximo no BNDES.
\end{abstract}

Palavras Chave: Gênero. BNDES. Machismo estrutural. Genealogia.

\section{GENDER AND THE BNDES: WOULD BE MORE STRUCTURAL MACHINES?}

\begin{abstract}
Maria Silvia Bastos Marques is a renowned economist at FGV and known for her pioneering role in her important movements in national prominent companies. She was a first and only woman president of Companhia Siderúrgica Nacional (CSN) and BNDES (National Bank for Economic and Social Development). This article aims to lead gender attitudes in male-dominated environments. From the observation of the board of BNDES presidents, a succession of men, in the occupation of the position, from the foundation until the year 2016/2017, when the cycle broke with the feminine indication. Our proposal is a biography of the trajectory of the single woman to compose this picture, making reflections on feminism and establishing a dialogue with an experience of a structural machismo. As a reference, it is based on the
\end{abstract}

\footnotetext{
${ }^{1}$ Graduada em Ciências Sociais pela Universidade Federal do Paraná. Especialista em Sociologia Política pela UFPR. Integrante do (NEP) Núcleo de Estudos Paranaenses - UFPR. Endereço eletrônico: estevinho_gomes@hotmail.com
} 
studies carried out by the NEP (Núcleo de Estudos Paranaenses), evaluating the conditions of long-term practice, while at the same time denoting the importance of women in genealogy studies. This strategy is present in environments such as politics, institutions and society as a whole. Proponents have access to a genealogy of power, taking into account gender issues, as well as their cultural, social and political capitals in relation to the burden. The profits are directed towards the capital that they aggregate and allow to break down barriers in some field within the social structure observing its action. A foliage linked to kinship, a building of social, cultural and professional capitals that provide reading, on the same conditions of access, an environment traditionally occupied by men? Our questions are the productions made by the NEP about family and kinship, as well as the commitment on the importance of women in the constitution of social space. The awakening will be analyzed biographically. This is a study that is part of the research in graduate programs (master's degree), where the biographies of BNDES presidents are being surveyed. This survey will be analyzed by prosopography, to understand the general profile of the presidents and the sense of influence in the guidelines adopted by the bank. Therefore, the problem is the identification of the woman's name to assume the maximum position in the BNDES.

Keywords: Gender. BNDES.Machismo estructural.Genealogia.

\section{Introdução}

A vida social da mulher começa a ser elaborada, pela leitura feminista, a partir do final do século XIX e início do século XX, em seu campo teórico e prático. Sendo, a partir da segunda metade do século XX, mais numerosas as produções teóricas sobre gênero, classe social, entre outros. Antes desse período a mulher era reservada de aparição pública. A socialização feminina era e, por vezes ainda é, com base na condição de submissão a figura masculina. Inseridas em um universo machista as mulheres participam da vida social com requintes de discriminação e desigualdade. Isso tende a ser negligenciado pela sociedade que, em geral, não debate o tema, naturalizando essa diferença. As questões de gênero, aqui abordadas, levarão em conta o trabalho feminino como o espaço público no qual, a classe social, é um fator de distinção.

Os movimentos sociais, têm importante contribuição na promoção do empoderamento das mulheres na esfera pública. Desde os anos 1960, o movimento feminista vem construindo sua história no debate sobre a participação da mulher no espaço social e, por consequência, na vida pública. Suas pautas passam por reconfigurações, dentro das demandas da sociedade atual.

Ideologicamente associadas ao romântico e a fragilidade, as mulheres, são sempre lembradas pelas flores e presentinhos em datas festivas e "comemorações", como é o caso do dia internacional da mulher, uma data simbólica decidida a partir de ideais marxistas, 
convencionada num contexto de luta e que, por conveniência do capitalismo ${ }^{2}$, na tentativa de descaracterizar tais lutas, adotam características que não condizem com seus motivos originais. Desse modo, cabe questionar quais as fronteiras entre o público e o privado e, em qual desses espaços o gênero se define. Qual é o gênero da modernidade? Questões de classe incidem sobre o gênero?

As mulheres entram no mundo do trabalho, em virtude da segunda guerra mundial, ocupando os postos deixados pelos homens (pois naquele momento encontram-se em batalha) mudando sua atuação, passando do espaço privado ao público. Essa nova frente de trabalho, absorve o público feminino, porém, não contempla a resolução das diferenças entre homens e mulheres no espaço público. O mercado de trabalho, embora seja regulamentado pela legislação trabalhista ${ }^{3}$, não é garantia de uma condição de igualdade, por exemplo salarial, ou seja, isso não dirimiu a desigualdade de gênero, fazendo com que homens com os mesmos cargos - executivos, políticos, e outros, recebam salários maiores, para o exercício da mesma função. Essa condição desigual de gênero tem sua origem no espaço doméstico e, não resolvida, é levada ao espaço público.

Este artigo, pretende dirigir um olhar às questões de gênero em ambientes de predominância masculina apontando para a biografia da única mulher a ocupar o cargo de presidente no BNDES, observando seus capitais sociais, culturais, econômicos e

\footnotetext{
${ }^{2}$ Decidido a partir do II Congresso Internacional de Mulheres Socialistas, em Copenhagem em 1910 e proposto por Clara Zetkin, deputada alemã e membro do Partido Comunista devido sua militância junto ao movimento operário e preocupação com a conscientização feminina. $\mathrm{O}$ fato é que ela não definiu uma data específica, porém atribui-se a ela tanto a data quanto a lembrança de um incêndio em Nova York no ano de 1857 que vitimou operárias no interior da fábrica. Ambos os países estavam empenhados na luta em favor das mulheres que, naquele momento, recebiam baixos salários, tinham uma jornada de trabalho exaustivo nas fábricas em semanas de 6 dias inteiros e parte do domingo e sem direito ao voto. A reconfiguração do significado afeta a modernidade especialmente porque cria um consolo com o objetivo de ocultar o debate sobre as diferenças salariais, as triplas jornadas de trabalho e o tempo livre em função dessa rotina. Disponível em: Blay, Eva Alterman. 08 de março: Conquistas e Controvérsias. Disponível em: $<$ http://www.scielo.br/pdf/ref/v9n2/8643>. consulta em 08/03/2019. Convêm ao capitalismo potencializar o comércio de flores, presentes, bombons entre outros fetiches, ocultando o sentido da luta histórica das mulheres de um ambiente opressor ainda na atualidade.

${ }^{3}$ Tanto o mercado de trabalho, quanto a política, colocam a mulher numa dimensão de análise do espaço público, ou seja, fora do espaço doméstico. Temos que a participação feminina na política, está regulamentada através lei 12.034/09, conhecida como a lei de cota,- o que garante em $30 \%$ a participação das mulheres em partidos políticos. A existência da lei não é sinônimo de redução das desigualdades, e não concretiza a adesão das mulheres, conforme tivemos a oportunidade de investigar em pesquisa realizada na Câmara Municipal de Pinhais, município da região metropolitana de Curitiba/PR, no período entre 1993 até o ano de 2016. Assim, observa-se que não é uma questão legal que rege essa relação estando mais próximo do estrutural, por onde caminharemos nessa análise.
} 
Revista NEP - Núcleo de Estudos Paranaenses, Curitiba, v.5, n.1, jun. 2019

políticos de atuação nos espaços sociais. Para esta investigação, foi realizado um levantamento biográfico da Presidente Maria Silvia Bastos Marques, através de notícias veiculadas na imprensa, dados biográficos da FGV, blogs e colunas sociais, de modo a analisar seu perfil, a partir de dimensões sociais e econômicas, tais como idade, estado civil, escolaridade, profissão e filiação partidária. Nossa investigação busca pensar como acontece a participação feminina, num universo dominado pela ideologia masculina. A atuação da mulher em um reduto historicamente masculino confere que tipo capitais a pessoa? Qual (is) característica (s) biográfica (s) se faz (em) presente?

Para a elaboração deste artigo, nos valemos dos debates de algumas autoras feministas, sobre o papel social da mulher na modernidade com seus avanços e retrocessos. Buscamos pensar o feminismo pelo binômio mulher e homem, e as posições ocupadas pela mulher dentro de um processo estruturado pela socialização, na composição do espaço social. Permeando todo o texto com o intuito de equacionar nosso referencial teórico, acionamos as noções de campo, habitus, trajetória e espaço social, no âmbito da trajetória da nossa biografada, extraídos dos conceitos elaborados por Pierre Bourdieu. Entendemos o campo como o lugar de formação intelectual do agente, aqui apontado pelo espaço de formação profissional, enquanto locus também da perpetuação de laços. Através do habitus é possível notar no agente a demonstração de um modus operandi, como um reflexo do seu processo de socialização. As instituições socializadoras do agente (família, escola, entre outras) comunicam sobre esse habitus que nos propomos observar, em sua trajetória. Dedicamos atenção aos aspectos relativos a divisão sexual do trabalho, chamando a atenção para as questões de gênero na modernidade, tentando entender como o avanço desse olhar é uma questão política com origens no espaço privado. Mulheres e seus capitais, através das produções elaboradas pelo NEP (Núcleo de Estudos Paranaense), dirigindo um olhar para a importância da mulher nas relações de parentesco. Em gênero e o BNDES, as conexões entre os capitais, apresentamos a possibilidade de refletir a condição do sucesso alcançado.

\section{MULHERES, FEMINISMO E PARTICIPAÇÃO POLÍTICA.}


Revista NEP - Núcleo de Estudos Paranaenses, Curitiba, v.5, n.1, jun. 2019

"Não se nasce mulher, torna-se mulher" Simone de Beauvoir ${ }^{4}$

Com essa máxima a autora consagra o existencialismo, enquanto corrente filosófica a qual pertence, mas também inspira o movimento feminista, na década de 1950, num levante pela igualdade de gênero. A própria história da autora é de rupturas com as imposições nas escolhas das mulheres de sua época, início do século XX. Inconformada com as opções dada as mulheres (casamento ou convento), trava uma luta contra esse "destino", constrói sua trajetória intelectual cursando Filosofia, na Sorbonne, ocupando os mesmos espaços de nomes como o de Jean Paul Sartre (seu companheiro), Maurice Merleau Poty, entre outros.

Seu contexto histórico está em construção, em relação a um olhar para a existência de um segundo sexo, imprimindo um legado inestimável de reflexões que subsidiaram os movimentos feministas e deram as mulheres condições de se compreender enquanto sujeito da história, ou seja, a subjetividade e as dimensões do "eu" passam a ser debatidas nos ciclos intelectuais a partir das ilações da autora em relação ao lugar que a mulher ocupa socialmente. Ao longo da história cada cultura elaborou, de modo diferente, o papel atribuído a mulher.

Até o século XIX a mulher era excluída de determinados ambientes, tidos como de exclusividade masculina, tais como espaços públicos e a política ${ }^{5}$. Vale lembrar que o direito ao voto feminino foi uma das primeiras reivindicações do movimento feminista. Nesse momento, o espaço público é requerido como um direito feminino, uma vez que no mercado de trabalho estavam em pleno exercício e atentas as injustiças da época.

O gênero "paira" sobre a modernidade, conforme Felski (1995) são as narrativas literárias, sociais e cotidianas que, de certo modo, determinam os papéis sociais, num universo de desigualdades que se reproduz em meio a modernidade por ser, ela mesma,

\footnotetext{
${ }^{4}$ Simone Lucie Ernestine Marie Bertrand de Beauvoir nasceu em 9 de Janeiro de 1908 em Paris, França filha da aristocracia frequentou até os 17 anos um liceu para meninas católica, onde aprendiam que ser mulher permite apenas duas alternativas na vida ou o casamento ou o convento. Em 1949, lança sua mais famosa obra: $\boldsymbol{O}$ segundo sexo onde consta a citada frase sendo bastante conhecida dentro do movimento feminista e difundindo-se como tema em várias categorias de análise.

${ }^{5}$ A primeira mulher a ocupar um cargo político em 1934 foi Carlota de Queirós, as condições dessas ocupações estavam condicionadas as condições de classe mas já motivam uma luta rompendo as barreiras de acesso ao "habitat masculino", conforme as autoras citam no artigo: A atuação política das vereadora na Câmara Municipal de Curitiba - CMC (2013-2015) Geissa Franco, Maiane Bittencourt e Jussara Cardoso. Memória Política de Curitiba - Anais / Ana Crhistina Vanali (org). Curitiba: Edições NEP, 2016.
} 
Revista NEP - Núcleo de Estudos Paranaenses, Curitiba, v.5, n.1, jun. 2019

um reflexo de narrativas de cunho machista. A partir desta autora, é possível pensar que a produção literária, marcou a civilização moderna moldando um ideal de virilidade ligado a figura masculina de alguns personagens ${ }^{6}$ que alimentaram, em seu enredo, o símbolo de uma construção de gênero que influencia as gerações, através do interacionismo simbólico ${ }^{7}$. O poder da narrativa, abordado por Felski, dialoga com o existencialismo presente na clássica frase de Beauvoir, no tocante a condição da mulher enquanto dependente da figura construída sobre o masculino. A compreensão dessa simbologia mobiliza mulheres na conquista por seu espaço dentro da sociedade. $\mathrm{O}$ voto inaugura a participação feminina, no final do século XIX e início do século XX incentivando a ocupação do espaço social e o clamor da sua voz através dos movimentos sociais.

Conforme análise de Adelman (2009), as vozes dos movimentos sociais ecoam por toda a sociedade dando vida ao "Outro", que fora ocultado nas narrativas. Ao abordar a gênese histórica e social do feminismo, aponta para a década de 1960, como um período em que ocorre a absorção das referências literárias (geração beat anos 50), cinematográficas, das revoltas com o que está estabelecido e principalmente pela crítica ao modelo vigente.

A autora mostra como a aproximação e o diálogo com o que até então era concebido como o "Outro" passa por uma reelaboração. Uma leva de contracultura adentra ao imaginário coletivo e, através dos jovens, a sociedade moderna passa por um profundo questionamento, transformada pela participação feminina em várias áreas, fazendo valer a máxima de que: "o lugar da mulher é onde ela quiser!"8 A modernidade não sustenta mais a invisibilidade feminina de outrora.

\footnotetext{
${ }^{6}$ Aos citar essas narrativas Felski estabelece um paralelo entre as simbologias associadas a esses personagens, gênero e modernidade. Desse modo, Berman ao descrever o casal Fausto e Gretchen a associa a um peso morto da tradição da qual o recém autônomo, ativo e autodefinido sujeito deve fugir. Em Flâneur de Baudelaire a figura do masculino é descrita como livre das amarras familiares e comunais, a modernidade é narrada como masculina.

${ }^{7} \mathrm{O}$ interacionismo simbólico ativa a introspecção do significado dos papéis sociais. Regula a conduta dos homens e, principalmente, das mulheres.

${ }^{8}$ Essas palavras de ordem são um protesto e fazem um contraponto a expressão:"lugar de mulher é na cozinha!" ou "lugar de mulher é no tanque!"
} 
Revista NEP - Núcleo de Estudos Paranaenses, Curitiba, v.5, n.1, jun. 2019

Desse modo, a sociedade moderna não pode desconsiderar a participação feminina em espaço público, no campo político ${ }^{9}$ e em carreiras executivas ${ }^{10}$. Pela observação do movimento feminista, é que importantes contribuições, nas conquistas obtidas, se fazem notar desde a conquista do voto até a participação em pleitos, assim como em cargos administrativos e em ambientes de predominância masculina. $\mathrm{O}$ movimento quebrou o silêncio imposto pela sociedade, elevou as mulheres a um patamar de luta e participação nas questões públicas do espaço social, o que não significou a plena aquisição dos direitos e um lugar confortável nas disputas de gênero.

\section{O espaço social estruturado}

Em pleno século XXI mulheres ainda driblam casa, relacionamentos, trabalho e estudo com as tarefas domésticas e o cuidado com os filhos. Suas jornadas triplicadas, implicam ainda em cobranças estéticas, ficando reservado aos homens o benefício da liberação das atividades domésticas e do espaço privado. A máxima do existencialismo, expresso por Beauvoir, é o entendimento de que homens e mulheres são socialmente construídos, não havendo determinações nem biológicas, nem psíquicas, nem econômicas que justifiquem a interpretações dos seus papéis sociais nem as diferenças as quais estão submetidas.

Biroli (2018) ${ }^{11}$ observa que os espaços domésticos compõem um ambiente onde a desigualdade se reproduz. A socialização imprime valores que são referência no espaço social e implicam em uma relação de poder vivenciado no cotidiano. Esses valores estão ainda calcados em um patriarcado e estruturam a sociedade como um todo. Na prática, a mulher, ao assumir o espaço público, carrega esses padrões de desvantagem produzidos no espaço privado de forma a dispor de seu corpo, seu tempo, sua energia de trabalho e

\footnotetext{
${ }^{9}$ No sentido de posição de mando seja em órgãos públicos ou na iniciativa privada.

${ }^{10}$ As mulheres vem assumindo altos postos executivos em escala mundial como é o exemplo recente de Gita Gopinath indicada para o cargo no Fundo Monetário Internacional (FMI); Pinelopi Koujianou ocupa a mesma função no Banco Mundial (BM) e Laurence Boone, na Organização para Cooperação e Desenvolvimento Econômico (OCDE). Três economistas nomeadas para a chefia dos departamentos econômicos das três instituições multilaterais de referência. Pozzi, Sandro. As três mulheres que lideram a análise econômica mundial. 04/10/2018

Disponível em:< https://brasil.elpais.com/brasil/2018/10/03/economia/1538556755 749295.html〉. Acesso em: 06/03/2019

${ }^{11}$ BIROLI, Flávia. Gênero e Desigualdades: Limites da democracia no Brasil. Boitempo. São Paulo, 2018.
} 
energia criativa. Desse modo, a vida pública da mulher é coberta de responsabilidades e filtros que exigem dela a execução de um papel semelhante ao exercido na domesticidade, como a cobrança de sua feminilidade. A forma da dualidade entre feminino e masculino é dada na divisão sexual do trabalho e, segundo a autora, produz o gênero posicionando as mulheres diferentemente e desigualmente segundo classe e raça.

O estudo desses espaços o doméstico como não remunerado, salvo pelo fato de ser executado fora de casa (cuidadoras, babás, domésticas), e o executado no espaço público enquanto atividade remunerada confere diferenças e atribui socialmente desigualdade e importância na execução entre homens e mulheres. Aqui repousa o cerne do debate de gênero da modernidade ligado as atividades tanto pela execução (feita pelo homem ou pela mulher) quanto pela remuneração. Segundo a autora, coletivamente a mulher é cobrada pelo cuidado com as crianças ao mesmo tempo que o homem é liberado dessa responsabilidade. O entendimento de que é o homem o provedor do lar, além de institucionalizar a liberação do espaço doméstico para o homem, desconsidera o trabalho que é exercido fora de casa, legitima a exploração, na esfera individual do trabalho da mulher pelo marido, que exige dela o cuidado das crianças, como uma atividade não remunerada e de sua responsabilidade. A remuneração da atividade é o ponto chave da relação entre gêneros e as relações desiguais do espaço social estruturando e legitimando o machismo.

A arena política é considerada pela autora, onde faz um diagnóstico das transformações recentes da participação feminina, analisando as posições concretas dos indivíduos nas relações de poder. A partir dessas premissas, avalia as formas assumidas dessas posições e suas lutas por direitos. Politicamente a legislação garante $30 \%{ }^{12}$ de participação feminina nas eleições proporcionais, o que não é o ideal de representação, ainda mais porque, efetivamente, apenas $10 \%$ de mulheres ocupam um cargo eletivo. No Brasil, tivemos no pleito de 2010 e 2014 a eleição de Dilma Roussef, a primeira mulher

\footnotetext{
12 Segundo TSE, sobre cotas de gênero: "Nas últimas eleições municipais, em 2016, apenas 31,89\% dos brasileiros que se candidataram eram mulheres. A primeira vez que as candidaturas femininas alcançaram $30 \%$ do total de candidaturas de um pleito no país foi nas eleições de 2012. Entretanto, desde 2009, a Lei das Eleições (Lei $\mathbf{n}^{\mathbf{0}}$ 9.504/1997) estabelece, em seu artigo 10, que, nas eleições proporcionais (para os cargos de deputado federal, estadual e distrital e de vereador), “(...) cada partido ou coligação preencherá o mínimo de $30 \%$ e o máximo de $70 \%$ para candidaturas de cada sexo". Ou seja, mesmo após sete anos da criação das chamadas "cotas de gênero", o número de mulheres candidatas alcançou pouco mais que o mínimo exigido." Disponível em: <http://www.tse.jus.br/imprensa/noticias-tse/2018/Marco/mulheresrepresentam-52-do-eleitorado-brasileiro>. Acesso em: 16/02/2019
} 
Revista NEP - Núcleo de Estudos Paranaenses, Curitiba, v.5, n.1, jun. 2019

presidente do país, sofrendo um ataque coletivo de misoginia e preconceito ${ }^{13}$ culminando, em 2016, no seu impeachment. Em $2018^{14}$ um novo pleito levou às urnas $52 \%$ de mulheres de todo o eleitorado uma conquista do movimento feminista do início do século no Brasil ${ }^{15}$.

\section{Mulheres, família e seus capitais}

O NEP - Núcleo de Estudos Paranaense, através do livro Nepotismo, Parentesco e Mulheres ${ }^{16}$ produz uma série artigos pensando no protagonismo das mulheres e suas relações parentais para efeito da análise das características políticas no Paraná. Análises

13 Analisando essa questão, observamos que a grande maioria dos candidatos à presidência são homens com mais 45 anos e com algumas exceções (Collor, Figueiredo) não estão livres da barriguinha e de cabelos brancos, do ponto de vista estético temos uma cobrança ainda maior para as mulheres. Dilma Rousseff sofreu uma série de ataques e foi condenada por pedaladas fiscais, prática comum entre os governos, mas que a enquadrou, deixando de ser logo após sua condenação. Conclui-se que o golpe fora articulado por uma questão de gênero.

${ }^{14}$ Disponível em < http://www.tse.jus.br/imprensa/noticias-tse/2018/Marco/mulheres-representam-52do-eleitorado-brasileiro >.consulta em 16/02/2018

${ }^{15}$ As mulheres conquistam o voto no Brasil a partir da constituição de 1932 assinada por Getúlio Dornelles Vargas mas efetivamente depositam seu primeiro voto nas urnas nas eleições de 1934. Conforme site do TRE, disponível em: <http://www.tre-pr.jus.br/imprensa/noticias-tre-pr/2018/Fevereiro/24-de-fevereirodia-da-conquista-do-voto-feminino-no-brasil-1 >.consulta em 16/02/2019

"A luta das mulheres brasileiras pelo direito ao voto teve início em 1891, quando foi rejeitada proposta de emenda à Constituição prevendo o direito de voto à mulher, mas, em 24 de fevereiro de 1932, o voto feminino no Brasil foi assegurado. Em 3 de maio de 1933, na eleição para a Assembleia Nacional Constituinte, a mulher brasileira, pela primeira vez, votou e foi votada em âmbito nacional. Com a Constituição de 1934, o voto feminino ganhou bases constitucionais. Se considerarmos que em 1893 a Nova Zelândia já concedia às mulheres o direito de voto, parece uma conquista tardia, mas, na França, isso só “ vez o eleitorado feminino superou em números absolutos o masculino. Já nas eleições de 2016, as eleitoras se tornaram maioria em todos os estados brasileiros. No total, dos 144 milhões de brasileiros aptos a votar, 75.226.056 eram mulheres, ou seja, representavam 52,24\% do eleitorado. Em 2018 não será diferente: a participação das eleitoras brasileiras será decisiva.

A iniciativa feminina é registrada com a primeira mulher a requerer seu direito no Brasil, conforme citação:"A primeira mulher a ter o direito de votar no Brasil foi Celina Guimarães Viana. E isso bem antes do Código Eleitoral de 1932. Aos 29 anos, Celina pediu em um cartório da cidade de Mossoró, no Rio Grande do Norte, para ingressar na lista dos eleitores daquela cidade. Junto com outras seguidoras, Celina votou nas eleições de 5 de abril de 1928. Formada pela Escola Normal de Natal, Celina aproveitou a Lei n॰ 660, de outubro de 1927, que estabelecida as regras para o eleitorado solicitar seu alistamento e participação. Em todo o país, o estado potiguar foi o primeiro a regulamentar seu sistema eleitoral, acrescentando um artigo que definia o sufrágio sem 'distinção de sexo'. O caso ficou famoso mundialmente, mas a Comissão de Poderes do Senado, não aceitou o voto. No entanto, a iniciativa da professora marcou a inserção da mulher na política eleitoral." Disponível em:< $\underline{\text { https://jornalggn.com.br/historia/a- }}$ conquista-do-voto-feminino-em-1932/ > consulta em: 16/02/2019.

16 O livro vai abordar a figura feminina, como fundamental, nas relações sociais mais amplas. Historicamente sucumbida pelo machismo reinante e pelo pensamento religioso, é o olhar treinado do cientista social que desperta a relevância de sua importante contribuição, que ultrapassa a esfera do lar e atenta para o fato de que os enlaces matrimoniais agregam valores sociais, culturais e políticos à sociedade paranaense, em vários períodos da história do Estado. 
Revista NEP - Núcleo de Estudos Paranaenses, Curitiba, v.5, n.1, jun. 2019

importantes, identificam na mulher uma rede de relações e uma estrutura do poder. $\mathrm{O}$ livro permite estabelecer uma relação entre mulheres, família e classe social. O casamento, aliado ao acúmulo de propriedade elevam a figura masculina a uma condição de status social. As mulheres dentro da genealogia possuem um valor para a interpretação da relação entre o público e o privado. As irmãs Correia de Freitas podem ser interpretadas como normativas da atuação da mulher no espaço público. São apontadas como representantes dos valores de uma época em que a mulher cuidadora adentra ao espaço público reproduzindo toda sua domesticidade enquanto cuidadora.

As primeiras Damas, são acolhidas pelo coletivo por representarem a condição de segundo lugar após a proeminência do marido como cargo diretivo na ordem política da federação. As deputadas, retratadas no livro, apontam para um problema na efetivação e pautas de ordem feminista, pois os padrões estabelecidos, desde seu ingresso, seguem uma ordem familiar de indicação e pertencimento, muito arraigado em nossa política em âmbito nacional. A lei das cotas permanece aquém do esperado e, efetivamente, não tem provocado muitas transformações no universo feminino referente a pautas aprovadas. Importante observar que as mulheres são abordadas em diferentes épocas traçando sua função na esfera doméstica, segundo um modelo convencionado e de época, até a esfera pública condizente com sua atuação política e, nesse campo, com sintomas do machismo estrutural por se tratar de um ambiente de predominância masculina.

O acesso a esses ambientes, por parte do público feminino, é uma associação entre capitais sociais e uma relação construída dentro de um habitus de classe num campo específico de produção de capitais culturais. A carreira de executiva é construída ao longo de uma trajetória e pertencimento. Assim o acesso a capitais culturais, confere a seus agentes uma condição de destaque dentro da estrutura social. Monteiro (2016) ${ }^{17}$ aponta para a importância do papel da instituição escolar no estudo das famílias e da formação de seus herdeiros, como indicativo de sucesso em sua trajetória política. A partir da comparação entre a as sociedades do passado com as da modernidade, faz a distinção entre o "sangue azul" e o "mérito pessoal", constrói seu argumento desmistificando a meritocracia mostrando as razões pelas quais o mundo moderno encontra-se carregado de

\footnotetext{
${ }^{17}$ Monteiro, José Marciano. A política como negócio de família: para uma sociologia política das elites e do poder político familiar. São Paulo: LiberArs, 2016.
} 
"violência simbólica" que se reproduzem impossibilitando o acesso a cargos, salários e bens.

Desse modo, a instituição escolar do agente é significativa, nesse estágio de socialização, Monteiro (2016) fornece-nos, ainda, indicativos ao estudo de trajetórias de sucesso. Nossa biografada Maria Silvia Bastos Marques, figura no cenário nacional em cargos de destaque em órgãos públicos e na iniciativa privada. Sua trajetória inclui a Fundação Getúlio Vargas ${ }^{18}$, instituição privada de formação, localizada no Rio de Janeiro de onde saíram nomes como Paulo Guedes ${ }^{19}$, Eduardo Suplicy, Mauro Moraes, Roberto Requião, Graça Foster, entre outros, que figuram como profissionais de protagonismo social e político.

$\mathrm{O}$ acesso a capitais culturais, conferem ao agente, condições de destaque na estrutura social, sobretudo na modernidade. A classificação pelo sangue citada por Monteiro (2016), é um indicativo de que a estrutura de poder e de sucesso na história, está diretamente ligada ao acesso aos bens materiais e não materiais. Essa linhagem confere um status social, em função do capital econômico desse agente. Na modernidade, o sangue não é citado, mas é sempre lembrado através do mérito. Os privilégios e, as injustiças se justificam pelo mérito. Um universo simbólico, é construído no imaginário coletivo infinitamente contrário ao real. Discursos da meritocracia incide em detrimento dos que não possuem esses capitais.

A instituição escolar possui grande influência nessa classificação por "mérito", na modernidade. Isso porque a formação escolar, foi instituída como necessária numa escala para a mobilidade social, conferindo ao agente um nível de status social. Assim, ao identificarmos na estrutura social o pertencimento a esse campo estamos indicando também a condição de classe, a formação dos seus capitais culturais, sobretudo acesso a carreira executiva e/ou política. A instituição a qual o agente frequenta é, portanto, um espaço social de contato entre famílias, cujos filhos se conhecem, frequentam os mesmos

\footnotetext{
${ }^{18}$ A Fundação Getulio Vargas é uma instituição brasileira de ensino superior, fundada em 20 de dezembro de 1944 com o objetivo inicial de preparar pessoal qualificado para a administração pública e privada do país.

${ }^{19}$ A partir da pesquisa, no site da FGV, através do quadro de ex alunos notáveis, observou-se nomes de políticos que atuaram e atuam no cenário Nacional, como é o caso do atual Ministro da Economia Paulo Guedes e o ex Governador e ex Senador Roberto Requião, da onde podemos observar, de imediato, que estamos tratando de um espaço de formação, especificamente frequentado por eleitos.
} 
Revista NEP - Núcleo de Estudos Paranaenses, Curitiba, v.5, n.1, jun. 2019

ambientes sociais (festas, clubes, viagens de férias) e podem vir a unir capitais, através de indicações a cargos e, até mesmo, pelos eventuais enlaces matrimoniais.

Importante salientar, no âmbito deste artigo, a contribuição de Bourdieu e Passeron $^{20}$ (2014), o quanto a identificação de variáveis como: origem social, sexo e gostos artísticos dos eleitos, carregam um peso significativo para sua formação. Os autores evidenciam que os filhos de profissionais liberais, tem suas chances aumentadas, em relação aos filhos dos trabalhadores assalariados agrícolas, na ordem de 58, 8\% para $0,7 \%$ essa diferença. Os dados apresentados fazem ruir a ideia de igualdade social propiciadas pelo ensino, apontando a categoria socio profissional dos seus progenitores como facilitadoras de acesso. A variável classe social encontra-se presente na análise e denota a distinção entre ser escolhido e fazer a escolha. Ambos dependem de um processo de socialização familiar que direcionam as profissões. O que varia aqui são as profissões escolhidas, aos que possuem um capital econômico a orientação será para cursos de melhor prestígio, já os oriundos da classe trabalhadora não terão a mesma "sorte". (Bourdieu. Passeron, 2014).

Analisa, ainda, que ser mulher na academia, implica em conformação ao espaço universitário. As questões de gênero, mapeiam comportamentos apontando para as desigualdades sociais no processo de escolha dos cursos. Aventurar-se intelectualmente para a mulher, é uma "doutrinação" de gestos, atitudes e palavras que as tornam "aceitáveis" no campo universitário, sendo mais cobradas em seus resultados positivos ou negativos, em função da coerção oferecida pelo campo, enquanto reduto classista e masculino. Essa relação promove um abismo entre a carreira a seguir e o desejo do agente causando desconforto as estudantes menos favorecidas, quando fruto de uma experiência negativa, porém, gera um sentimento de gratidão para os casos de mobilidade vertical ascendente. Os filhos da classe trabalhadora raramente terão a oportunidade de seguir carreira universitária com exclusividade pois o trabalho os espera, esse é um privilégio reservado apenas aos herdeiros.

\footnotetext{
${ }^{20}$ BOURDIEU, Pierre; PASSERON, Jean-Claude. Os Herdeiros: estudantes e a cultura. Trad. Ione Ribeiro Valle e Nilton Valle. Florianópolis: Editora da UFSC, 2014. Ao estudar a França na década de 1960, revelam, a partir de variáveis como classe, sexo e arte, as desigualdades do ambiente acadêmico.
} 
Revista NEP - Núcleo de Estudos Paranaenses, Curitiba, v.5, n.1, jun. 2019

Classe e gênero, também são apontadas como variável para a desigualdade das escolhas, em Biroli (2018), o peso dessa variável reflete em formas de acesso - a formação, por exemplo - pelo critério do tempo e da renda. Basta observar que dentro dessa lógica, o tempo livre feminino é tomado com as tarefas domésticas. Os custos desse trabalho não são remunerados, pois dentro da lógica estruturada do machismo é dever da mulher realizá-lo. Nestas condições, portanto, entrar em uma universidade demanda muito mais empenho ao público feminino.

Assim, podemos considerar que exercer um cargo dentro de um ambiente predominantemente masculino gera uma série de "desconforto" as mulheres, caso não pertençam a uma classe social abastada. A determinação e esforço devem ser sinônimo de disciplina e postura diante dos desafios da profissão e da vida social, uma questão de perseverança para romper essas barreiras. As mulheres na política, motivam pesquisas que apontam para a restrição na elaboração de pautas, que não ampliam o leque das questões feministas, por exemplo, girando em torno apenas de temas "permitidos" a esse público $^{21}$.

\section{Por fim o gênero e BNDES}

Desse modo, os cargos ocupados, por Maria Silvia Bastos Marques, ao longo da sua trajetória profissional, sempre lhe renderam um olhar quanto ao seu pioneirismo. Essa característica está atrelada a sua história pessoal e, também, a seu capital econômico, sendo a primogênita, e única mulher de uma família de quatro filhos, assume a qualidade de estar sempre a frente dos espaços de predominância masculina. A referência familiar é significativa para impulsionar suas escolhas e protagonismo social. Filha do médico, diretor do Hospital São Francisco e Secretário de Saúde de Itabapoana, Ruy Pimentel Marques, tem seu protagonismo iniciado na esfera doméstica, quando decide estudar Administração no Rio de Janeiro, decisão que conta com apoio materno. Do lado materno, acumula capital cultural ligado as artes e as letras. Seu avô materno além de

\footnotetext{
${ }^{21}$ Para aprofundamento desse assunto consultar os artigos em: Nepotismo, Parentesco e Mulheres, fundamentalmente de seu organizador Ricardo Costa Oliveira, Mônica Helena Harrich Silva Goulart e Natália Cristina Granato, entre outros de suma importância para compreensão do familismo e da dinâmica política pelo parentesco.
} 
Revista NEP - Núcleo de Estudos Paranaenses, Curitiba, v.5, n.1, jun. 2019

fundador do jornal Fluminense, ativo ainda hoje, é dono da escola particular Rio Branco, na qual Maria Silvia estudou. Ao crescer em um ambiente assim, pode desfrutar de tempo e experiências de vida que lhe permitiram escolher outro destino que não do da esfera doméstica. Como herdeira, tem sua trajetória favorecida pelo seu capital econômico e cultural. $^{22}$

Seu protagonismo é regado de uma boa formação escolar e aperfeiçoado pelas especializações na EBAP e FGV. Os enlaces matrimoniais também corroboram para a manutenção do status, em seu primeiro casamento tem como sogro Hélio Fernandes (irmão de Millôr Fernandes), que como o avô materno, possui um Jornal, o Tribuna da Imprensa, participando da história política do Brasil. Como jornalista fez a cobertura, após o final do Estado Novo da Assembleia Constituinte de 1946, mantendo longa relação de amizade com Carlos Lacerda, que ao se eleger governador da Guanabara concede ao amigo a posse do jornal que havia fundado. Foi assessor de imprensa de Juscelino Kubitscheck, durante a campanha à presidência da república em 1955, depois fazendolhe oposição. Perseguido, antes mesmo do golpe de 1964 por ordem de Jair Dantas Ribeiro, Ministro da guerra de João Goulart, é preso e libertado após onze dias por ordem do STF (Supremo Tribunal Federal). Torna-se relator da Frente Ampla chegando a ser candidato a Deputado Federal pelo MDB, mas é cassado em $1966^{23}$.

Em segunda núpcias tem como esposo o economista carioca Sérgio Ribeiro da Costa Werlang ${ }^{24}$, sendo identificado como "a menina dos olhos" do ex-ministro da Fazenda Mário Henrique Simonsen e considerado como um dos seus alunos mais brilhantes. O grupo se completa com Daniel Dantas, diretor do banco Opportunity, e John Harris, do banco Boreal. Após a morte de Simonsen em 1997, Werlang, assume a diretoria do Banco Central. Nesse período já é pai dos gêmeos Catarina e Olavo. Maria Silvia e

\footnotetext{
${ }^{22}$ Vontade Inabalável: Os erros e acertos de uma executiva pioneira. Disponível em: <https://www.amazon.com.br/Vontade-inabal\%C3\%A1vel-acertos-executiva-pioneiraebook/dp/B07JJMP3LB >.Acesso em 26/05/2019

23 Pesquisa Hélio 3 Fernandes. Disponível em: <https://pt.wikipedia.org/wiki/H\%C3\%A9lio_Fernandes >.Acesso em: 26/05/2019

24 Folha de São Paulo. Werlang era discípulo de Simonsen. 11 fev 1999. Mercado. Disponível em: $<$ https://www1.folha.uol.com.br/fsp/dinheiro/fi11029911.htm $>$.

e Acervo história oral. Verbete entrevista temática. Sérgio Werlang.

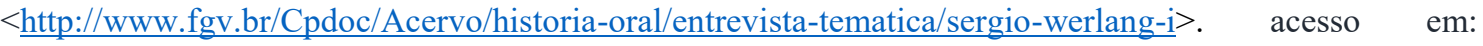
$10 / 03 / 2019$
} 
Revista NEP - Núcleo de Estudos Paranaenses, Curitiba, v.5, n.1, jun. 2019

Werlang se conheceram pelo amigo em comum Eduardo Modiano $^{25}$, filho do francês Umberto Modiano que veio ao Brasil e fez fortuna com a exportação do café 1947 e mudou para o ramo da hotelaria em búzios na década de 1980, economista e ex-presidente do BNDES esteve a frente ao programa de desestatização durante o governo de Fernando Henrique Cardoso.

Nossa biografada é um reflexo da modernidade como as economistas Gita Gopinath, Laurence Boone e Pinelopi Koujianou, que recentemente quebraram a alta hierarquia econômica global, assumindo cargos importantes, em um ambiente tradicionalmente dominado por homens. Elas assumem respectivamente o comando do Fundo Monetário Internacional (FMI), Banco Mundial (BM) e a Organização para Cooperação do Desenvolvimento Econômico (OCDE) ${ }^{26}$.

Os capitais econômicos e culturais, constituem as bases de formação de um agente, orientam suas escolhas, consolidando seus laços numa carreira de sucesso. A trajetória destes agentes é favorecida pelo nascimento, agregando capitais familiares frequentando e ampliando seus ciclos relacionais e se perpetuando em cargos, indicações favoráveis. Desse modo, usufruem de condições para construção de um capital social com sólidos elos, para galgar postos de proeminência. O capital cultural, é alimentado em ciclos herdados pelo capital familiar e, como herdeiros, escolhem seus caminhos e são escolhidos em posição de mando ou inéditas, o que lhes é computado como mérito. $\mathrm{O}$ gênero interfere menos nesse processo uma vez que o sustento da posição vem dos capitais que agregam. Dito de outro modo, ser mulher "bem nascida" impacta menos sobre sua carreira.

\section{Conclusão}

\footnotetext{
${ }^{25}$ Para aprofundamento ler Kluger, Elisa. Meritocracia de laços:gênese e reconfigurações do espaço dos economistas no Brasil. São Paulo, 2017 tese de doutorado disponível em: <file:///C:/Users/estev/OneDrive/Documentos/Nova\%20pasta/meritocracia\%20de\%20laços\%20elisa\%20 kluger.pdf > . Acesso em: 26/05/2019 e também verbete biográfico Eduardo Modiano disponível em: $<$ http://www.fgv.br/cpdoc/acervo/dicionarios/verbete-biografico/eduardo-marco-modiano>. Acesso em: $26 / 05 / 2019$

${ }^{26}$ As três mulheres que lideram a análise da economia mundial. El país. Economia. 05/10/2018. Disponível em:< https://brasil.elpais.com/brasil/2018/10/03/economia/1538556755_749295.html >. Acesso em 06/03/2019.
} 
Revista NEP - Núcleo de Estudos Paranaenses, Curitiba, v.5, n.1, jun. 2019

Objetivamos, com este trabalho, construir uma reflexão à cerca da ocupação do cargo de presidente dentro do BNDES, por uma única mulher. Nossa análise girou em torno das questões de gênero, justificada pelo fato de que ao longo, dos seus 67 anos de existência do BNDES e, após 39 presidentes (em 2019), a única mulher a cumprir essa função foi, nossa biografada, Maria Silvia Bastos Marques. O debate de gênero nos instigou a imaginar as razões para que esse fato fosse possível. Buscamos na literatura feminista os argumentos sobre o machismo estrutural, verificamos que atitudes preconceituosas são definidas no espaço doméstico e reproduzidas no espaço público, dificultando ainda mais a atuação das mulheres em ambientes de tradição masculina, especialmente para as que não pertencem a uma classe social capaz de agregar capital cultural e social, entre outros.

No âmbito dessa investigação pudemos perceber essa ruptura a partir de alguns fatores. O fato de possuir um sólido capital cultural, econômico e social foram determinantes para o acesso a postos diretivos no espaço público. As conexões estabelecidas em determinadas instituições, como a FGV, permitiram agregar valores como, amizades de longa duração, que no decorrer dos acontecimentos, se transformaram em indicações. Os enlaces matrimoniais foram também uma forma de agregar capitais e consolidar contatos promissores, indicações e cargos.

Nossa análise, buscou em Bourdieu o referencial teórico verificando as condições de construção dos capitais culturais que envolveram a trajetória de Maria Silvia Bastos Marques sem esquecer o poder das famílias e dos casamentos. Em sua família o fato de ser a única mulher, entre os quatro filhos do casal, pesou favoravelmente em seu pioneirismo. Sua formação acadêmica consolidou fortes laços que garantiram também seu protagonismo. A tão almejada carreira de professor, de expectativa familiar - a exemplo de sua mãe, Maria Alexandrina que foi, também, diretora do conservatório de música - a fez decidir pela Administração a princípio e posteriormente, com as especializações, mestrado e doutorado, em economia, na Fundação Getúlio Vargas (FGV) - que se tornou referência na formação em Economia, desde a sua fundação em 1940, no Rio de Janeiro e com o objetivo de formar pessoal qualificado para atuar no setor público. Além da nossa biografada, formou ainda "uma galeria de ex alunos notáveis" que atuaram e atuam na política desde então, como é o caso do atual Ministro da Economia, Paulo Guedes. 
Revista NEP - Núcleo de Estudos Paranaenses, Curitiba, v.5, n.1, jun. 2019

Todo pioneirismo foi marcado por um processo de socialização que a incentivou a romper barreiras, acrescentamos a isso o fato ser proveniente de uma família consolidada e herdeira de um capital econômico de longa duração, pelo lado paterno vem de uma família proprietária de terras, dedicados ao cultivo do café e criação de gado. Pelo lado materno, recebe o domínio da imprensa escrita e a atuação em obras importantes como a estrada de ferro Leopoldina Railway em campos de Guaytacaze, mas foi em Bom Jesus de Itabapoana, cidade capixaba, que sua história começa. Desse modo, sua trajetória foi fortalecida em um ambiente propiciado pelos seus antepassados. Seu pai consolida esse status quo, exercendo a profissão de médico e, também, Secretário de Saúde. Todos esses condicionantes, agregados a sua trajetória contribuíram significativamente, com a obtenção desses resultados, os quais buscamos apresentar neste artigo.

\section{Referências}

ADELMAN, M. A voz e a escuta: encontros e desencontros entre a teoria feminista e a sociologia contemporânea. SP: Editora Blucher, 2009.

BEAUVOIR, Simone. O segundo sexo. Rio de Janeiro. Nova Fronteira,1980

BIROLI, Flávia. Gênero e Desigualdades: Limites da democracia no Brasil. São Paulo. Boitempo, 2018.

BLAY, Eva Alterman: 8 de março: conquistas e controvérsias. Estudos Feministas. Scielo Brasil, 2001. Disponível em: 〈http://www.scielo.br/pdf/ref/v9n2/8643 >. Acesso em 08 março 2019

BOURDIEU, Pierre. O Poder simbólico. Rio de Janeiro: Beltrand Brasil. 2012

BOURDIEU, Pierre; PASSERON, Jean-Claude. Os Herdeiros: estudantes e a cultura. Trad. Ione Ribeiro Valle e Nilton Valle. Florianópolis: Editora da UFSC, 2014

FELSKI, Rita. The Gender of Modernity. Cambridge, Mass./London: Harvard University Press, 1995

KLUGER, Elisa. Meritocracia de laços: gênese e reconfigurações do espaço dos economistas no Brasil. São Paulo, 2017. Tese de doutorado. Disponível em: 
Revista NEP - Núcleo de Estudos Paranaenses, Curitiba, v.5, n.1, jun. 2019

<file:///C:/Users/estev/OneDrive/Documentos/Nova\%20pasta/meritocracia\%20de\%20la ços\%20elisa\%20kluger.pdf >. Acesso em: 20 janeiro 2018

MONTEIRO, José Marciano. A política como negócio de família: para uma sociologia política das elites e do poder político familiar. São Paulo: LiberArs, 2016

OLIVEIRA, Ricardo Costa de. Na teia do nepotismo: sociologia política das relações de parentesco e poder político no Paraná e no Brasil. Curitiba: Editora Insight, 2012.

OLIVEIRA, Ricardo Costa de. O silêncio dos vencedores: genealogia, classe dominante e Estado do Paraná. Curitiba: Editora Moinho do Verbo, 2001

SCHMIDT, Maria Auxiliadora e GARCIA, Tânia Maria F. Braga. Recriando histórias de Pinhais. Curitiba: TMF Braga Garcia, 2000.

\section{Referências biográficas}

Verbete biográfico Gustavo Loiola. Disponível em:

$<$ http://www.fgv.br/cpdoc/acervo/dicionarios/verbete-biografico/gustavo-jorgelaboissiere-loiola >. Acesso em: 06 março 2019.

Folha UOL Werlang era discípulo de Simonsen. Folha de São Paulo 11/02/1999. Disponível em: < https://www1.folha.uol.com.br/fsp/dinheiro/fi11029911.htm >. Acesso em: 10 março 2019.

Acervo CPDOC entrevista temática Sérgio Werlang. Disponível em: $\langle$ http://www.fgv.br/Cpdoc/Acervo/historia-oral/entrevista-tematica/sergio-werlang-i $>$. Acesso em: 10 março 2019.

Acervo CPDOC verbete biográfico Armínio Fraga. Disponível em: $\langle$ http://www.fgv.br/cpdoc/acervo/dicionarios/verbete-biografico/fraga-arminio $>$. Acesso em: 22 março 2019.

AMN - Academia Nacional de Medicina. Silvio Fraga (cadeira n5). Disponível em: <http://www.anm.org.br/conteudo_view.asp?id=685 >. Acesso em: 22 março 2019 Acervo CPDOC verbete geográfico Carlos Ivan Simonsen. Disponível em: $<$ http://www.fgv.br/cpdoc/acervo/dicionarios/verbete-biografico/leal-carlos-ivan-

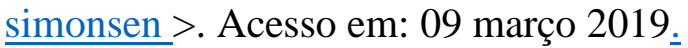

Acervo CPDOC verbete biográfico Mario Henrique Simonsen. Disponível em: $<$ http://www.fgv.br/cpdoc/acervo/dicionarios/verbete-biografico/simonsen-mariohenrique >. Acesso em: 08 março 2019.

Acervo CPDOC. Verbete biográfico. Gustavo Franco. Disponível em: $\langle$ http://www.fgv.br/cpdoc/acervo/dicionarios/verbete-biografico/franco-gustavo >. Acesso em: 07 março 2019. 
Revista NEP - Núcleo de Estudos Paranaenses, Curitiba, v.5, n.1, jun. 2019

Executiva diz que culpa é a principal inimiga da mulher. Cidade Verde Notícias.

Economia. Piauí. 06 março 2010. Disponível em:

$<$ https://cidadeverde.com/noticias/54321/executiva-diz-que-culpa-e-a-principal-inimigada-mulher-que-trabalha_ >. Acesso em: 06 março 2019.

BNDES imprensa. Foto de Maria Silvia Bastos Marques. Disponível em:

<https://www.facebook.com/bndes.imprensa/posts/a-presidente-do-banco-nacional-dedesenvolvimento-econ\%C3\%B4mico-e-social-bndes-maria/1047144318712741/ >.

Acesso em: 05 março 2019.

Isto é Gente. O poder da paixão. 25 junho de 2001 Disponível em:

<http://www.terra.com.br/istoegente/99/reportagem/david_maria.htm>. Acesso em: 04 março 2019.

Folha de São Paulo. Joyce Pascowitch. 08 de março de 1998. Disponível em:

<https://www.amazon.com.br/Vontade-inabal\%C3\%A1vel-acertos-executiva-pioneiraebook/dp/B07JJMP3LB >. Acesso em: 04 março 2019.

Presidente do BNDES Maria Silvia Bastos Marques pede demissão ao Presidente

Michel Temer. G1. Brasilia. 26 de maio de 2017. Disponível em:

$<$ https://g1.globo.com/economia/noticia/presidente-do-bndes-maria-silvia-bastos-pededemissao-ao-presidente-michel-temer.ghtml >. Acesso em: 04 mar. 2019.

As três mulheres que lideram a análise da economia mundial. El País. Economia. 05 out 2018. Disponível em:

<https://brasil.elpais.com/brasil/2018/10/03/economia/1538556755_749295.html >.

Acesso em:06 março 2019.

ANEXO I - BIOGRAFIA

\begin{tabular}{l} 
MARIA SILVIA BASTOS MARQUES \\
\hline PRESIDENTE: MICHEL TEMER \\
\hline PERÍODO DA HISTÓRIA: DEMOCRACIA \\
\hline GESTÃO: MAIO 2016 a MAIO 2017 \\
\hline FILIAÇÃO: RUY PIMENTEL MARQUES E \\
\hline MARIA ALEXANDRINA \\
\hline
\end{tabular}

27 Disponível em : https://www.facebook.com/bndes.imprensa/posts/a-presidente-do-banco-nacional-dedesenvolvimento-econ\%C3\%B4mico-e-social-bndes-maria/1047144318712741/ acesso em 05/03/2019 
Revista NEP - Núcleo de Estudos Paranaenses, Curitiba, v.5, n.1, jun. 2019 Dossiê Partidos Políticos e Conexões Familiares

ISSN: $2447-5548$

LOCAL E DATA DE NASCIMENTO: 27/12/1956 - BOM JESUS DO ITABAPOANA/ RJ

FORMAÇÃO/PROFISSÃO:

1979 - BACHAREL EM ADMINISTRAÇÃO PÚBLICA PELA ESCOLA BRASILEIRA DE ADMINISTRAÇÃO PÚBLICA (EBAP) DA FUNDAÇÃO

GETULIO VARGAS (FGV)

1982 - MESTRE ECONOMIA - EBAP/FGV

1987 - DOUTORA EM ECONOMIA PELA ESCOLA DE PÓS-GRADUAÇÃO EM ECONOMIA (EPGE) DA FGV.

CARREIRA:

1982 - 1989 - ECONOMISTA DO CENTRO DE ESTUDOS MONETÁRIOS E DE ECONOMIA INTERNACIONAL DO INSTITUTO BRASILEIRO DE ECONOMIA (IBRE) DA FGV

1985 - 1990 - PROFESSORA ASSISTENTE NO DEPARTAMENTO DE ECONOMIA DA PONTIFÍCIA UNIVERSIDADE CATÓLICA DO RIO DE JANEIRO

1990 - 1991 - COORDENADORA DA ÁREA EXTERNA DA SECRETARIA DE POLÍTICA ECONÔMICA DO MINISTÉRIO DA ECONOMIA, FAZENDA E PLANEJAMENTO

1991 - 1992 - ASSESSORA ESPECIAL PARA ASSUNTOS DE DESESTATIZAÇÃO DO BNDES E DIRETORA DAS ÁREAS FINANCEIRA E INTERNACIONAL E DE PLANEJAMENTO DO BANCO NACIONAL DE DESENVOLVIMENTO ECONÔMICO E SOCIAL (BNDES)

1993 - 1996 - SECRETÁRIA MUNICIPAL DE FAZENDA DA PREFEITURA DO RIO DE JANEIRO NA GESTÃO DO PREFEITO CESAR MAIA

1996 -1999 - DIRETORA SUPERINTENDENTE DO CENTRO CORPORATIVO DA COMPANHIA SIDERÚRGICA NACIONAL (CSN)

1999/2002 - NO SETOR PRIVADO, PRESIDIU A COMPANHIA SIDERÚRGICA NACIONAL (CSN) E O INSTITUTO BRASILEIRO DE SIDERURGIA. FOI PRESIDENTE DA ICATU SEGUROS E SÓCIA DA MS \& CR2 FINANÇAS CORPORATIVAS.

PARTICIPOU DE DIVERSOS CONSELHOS DE ADMINISTRAÇÃO, NO BRASIL E NO EXTERIOR, DE EMPRESAS COMO VALE, SOUZA CRUZ, PETROBRAS, EMBRATEL, ARCELOR, ANGLO AMERICAN, GRUPO PÃO DE AÇÚCAR E LIGHT, ENTRE OUTRAS.

2011/2014 - FOI PRESIDENTE DA EMPRESA OLÍMPICA MUNICIPAL DESDE SUA CRIAÇÃO

2016 - PERMANECENDO ATÉ ABRIL COMO ASSESSORA ESPECIAL DO PREFEITO PARA AS OLIMPÍADAS

PREMIAÇÕES:RECEBEU VÁRIOS PRÊMIOS DE RECONHECIMENTO NO BRASIL E NO EXTERIOR AO LONGO DE SUA VIDA PROFISSIONAL.

2001/2002 - EXECUTIVO DE VALOR, POR DOIS ANOS SUCESSIVOS; GLOBAL LEADER OF TOMORROW

1999 - PELO WORLD ECONOMIC FORUM; LÍDER EMPRESARIAL MERCOSUL - BRASIL

1999 - PELO FÓRUM DE LÍDERES DO MERCOSUL; E PELA TIME MAGAZINE

1997 - O ONE OF THE 12 TOP EXECUTIVES OF THE WORLD.

FILIAÇÃO PARTIDÁRIA: PFL (1990 SENDO PRÉ CANDIDATA A PREFEITURA DO RIO DE JANEIRO, QUANDO FOI SECRETÁRIA DO ESPORTE NA ADMINISTRAÇÃO) ATUALMENTE É FILIADA AO DEM

CAPITAIS FAMILIARES ${ }^{28}$ : PAI O MÉDICO RUY PIMENTEL MARQUES DIRETOR DO HOSPITAL SÃO FRANCISCO DE PAULO E POR DUAS VEZES SECRETÁRIO DE SAÚDE DA SUA CIDADE E MÃE MARIA ALEXANDRINA PROFESSORA E DIRETORA DO CONSERVATÓRIO DE MÚSICA. FILHA MAIS VELHA DE QUATRO IRMÃOS ( RUY, MARCO ANTONIO E PAULO CESAR) A ÚNICA MENINA PIONEIRA DESDE PEQUENA, CONQUISTOU A LIBERDADE DE IR ESTUDAR NA CIDADE GRANDE AOS 16 ANOS. AVÓS PATERNOS MARIA DAS DORES E JOSÉ OLIVEIRA MARQUES TRABALHAVAM COM CAFÉ E GADO RUY ESTUDOU EM MUQUI NO ESPIRITO SANTO E CURSOU MEDICINA NA TRADICIONAL MEDICINA E CIRURGIA QUE VIROU UNIRIO. BISAVÔ MATERNO, ANIBAL LOPES, DONO DE UM PERIÓDICO JORNAL DO POVO EM PONTE NOVA, MINAS GERAIS. AVÓS MATERNO CÉLIA E ÉSIO MARTINS BASTOS TAMBÉM JORNALISTA TRABALHAVA NA ESTRADA DE FERRO LEOPOLDINA RAILWAY EM CAMPOS DO GUAYTACAZE. APÓS O CASAMENTO MUDARAM-SE PARA BOM JESUS DO NORTE, ESPIRITO SANTO PEQUENA CIDADE DE BOM JESUS DE ITABAPOANA. FUNDARAM EM 1946 UM JORNAL O JORNAL FLUMINENSE QUE CIRCULA AINDA HOJE. DESDE CRIANÇA PODE ACOMPANHAR A PRODUÇÃO ARTESANAL DOS JORNAIS DA ÉPOCA. ESTUDOU NO GRUPO ESCOLAR PRIMEIROS PASSO CONCEITUADA ESCOLA PÚBLICA E OS ANOS FINAIS EM COLÉGIO PARTICULAR COLÉGIO RIO BRANCO DE PROPRIEDADE DO SEU AVÔ MATERNO, O PAI QUERIA QUE ELA FIZESSE O NORMAL E NÃO O CIENTÍFICO, ENTÃO ELA DIVIDIU SUA FORMAÇÃO ENTRE O NORMAL E O PREPARATÓRIO PARA O VESTIBLAR EM ESCOLA PÚBLICA COLÉGIO ESTADUAL PADRE MELLO E ENTRE UM E OUTRO ESTUDAVA PIANO. PASSOU NO VESTIBULAR AOS 17 ANOS NA UEG (DEPOIS UERJ) SEUS IRMÃO MARCO ANTONIO E PAULO SÉRGIO NO COLÉGIO SÃO BENTO - TIVERAM QUE ACOMPANHAR A IRMÃ NA IDA PARA UNIVERSIDADE E HOSPEDARAM-SE NA CASA DA TIA LEDA GARCIA MARQUES. COMO OCURSO DE ADMINSTRAÇÃO ERA NOTURNO SEU PAI CONSEGUIU TRANSFERÍ-LA PARA (EBAP) ESCOLA BRASILEIRA DE ADMINSTRAÇÃO PÚBLICA NA (FGV) FUNDAÇÃO GETÚLIO VARGAS, O QUE FOI DECISIVO EM SUA TRAJETÓRIA. AVÔ MATERNO JORNALISTA E VEREADOR EM BOM JESUS DE ITABAPOANA, TAMBÉM CANDIDATO A PREFEITO E DEPUTADO ESTADUAL FOI FILIADO AO PSDB E DEPOIS AO MDB, FAZIA OPOSIÇÃO AO REGIME MILITAR TINHA MUITAS HISTÓRIAS QUE ELA ADORAVA OUVIR, SUA MÃE TAMBÉM SE INTERESSA POR POLÍTICA E MANIFESTA APOIO A CANDIDATOS DE SUA PREFERÊNCIA. SUA FORMAÇÃO NA FGV RENDEU-LHE POSTERIOR CONTATO - CONCORCET REZENDE PROFESSOR DE DIREITO TRIBUTÁRIO E DEPOIS COLEGA NA SECRETARIA DA FAZENDA. PRESIDENTES DO BACEN EX COLEGAS DE ECONOMIA ARMINIO FRAGA, GUSTAVO FRANCO E GUSTAVO LOYOLA. ARMINIO FRAGA E GUSTAVO FRANCO FORAM PARA PUC E

${ }^{28}$ MARQUES, Maria Silvia Bastos. Vontade inabalável: os erros e acertos de uma executive pioneira. Editora Sextante. Rio de Janeiro. 2018. Escrito após sua saída do BNDES. Disponível em: https://www.amazon.com.br/Vontade-inabal\%C $3 \%$ Alvel-acertos-executiva-pioneira-

ebook/dp/B07JJMP3LB. Acesso em: 05/03/2019 
Revista NEP - Núcleo de Estudos Paranaenses, Curitiba, v.5, n.1, jun. 2019

DESPOIS EUA MARIA SILVIA E GUSTAVO LOYOLA PERMANECERAM NA FGV AS RAZOES PARTICULARES DE MARIA SILVIA ERA A INTENÇÃO DE CURSAR EM SEGUIDA O DOUTORADO NO MESTRADO ESTUDOU COM SHIRLENE RAMOS QUE FEZ CARREIRA NO IBGE. TAMBÉM FOI COLEGA DE CARLOS IVAN SIMONSEN LEAL PRESIDENTE DA FGV DESDE 2000. SERGIO RIBEIRO DA COSTA WERLANG PAI DOS GÊMEOS CATARINA E OLAVO E EM 1999 DIRETOR DA POLÍTICA ECONÔMICA DO BACEN. TAMBÉM ANTONIO CARLOS FIGUEIREDO PINTO PROFESSOR DA PUC/RJ, TODOS ENGENHEIROS. SEU MESTRADO SE INICIOU EM 1979 E PROFESSOR MARIO HENRIQUE SIMONSEN ANO DO SEU RETORNO A DIREÇÃO DA PÓS-GRADUAÇÃO APÓS TER SIDO MINISTRO DA FAZENDA E DO PLANEJAMENTO DOS GOVERNO ERNESTO GEISEL E JOÁO BAPTISTA FIGUEIREDO.

FILHOS: CATARINA MARQUES WERLANG E OLAVO WERLANG

PARENTESCO: VIÚVA DO JORNALISTA RODOLFO FERNANDES (FILHO DE HELIO FERNANDES DONO DO JORNAL TRIBUNA DA IMPRENSA E DIRETOR DO JORNAL O GLOBO NO RJ. SOBRINHO DE MILLÔR FERNANDES) - DIRETOR DE REDAÇÃO DO JORNAL O GLOBO

FOI CASADA, EM SEGUNDA NÚPCIAS, COM SÉRGIO WERLANG, DIRETOR DO BANCO CENTRAL NO GOVERNO FHC

Fonte: Quadro elaborado pela autora.

ANEXO II - CAPITAL CULTURAL E CONEXÕES

\begin{tabular}{|l|l|l|l|l|}
\hline Agente & Doutorado & Ano & Cargo & $\begin{array}{l}\text { Capital } \\
\text { familiar }\end{array}$ \\
\hline $\begin{array}{l}\text { GUSTAVO } \\
\text { LOYOLA }\end{array}$ & FGV -1982 & $1995 / 1997$ & $\begin{array}{l}\text { PRESIDENTE } \\
\text { BANCO } \\
\text { CENTRAL }\end{array}$ & $\begin{array}{l}\text { Pai: } \\
\text { economista } \\
\text { Mãe: não } \\
\text { encontrado }\end{array}$ \\
\hline $\begin{array}{l}\text { GUSTAVO } \\
\text { FRANCO }\end{array}$ & $\begin{array}{l}\text { FGV } \\
\text { HARVARD(EUA) } \\
-1986\end{array}$ & $1997 / 1998$ & $\begin{array}{l}\text { PRESIDENTE } \\
\text { BANCO } \\
\text { CENTRAL }\end{array}$ & $\begin{array}{l}\text { Pai: } \\
\text { advogado } \\
\text { Mãe: }\end{array}$ \\
\hline $\begin{array}{l}\text { ARMÍNIO } \\
\text { FRAGA } \\
\text { NETO }\end{array}$ & $\begin{array}{l}\text { PRINCETON(EUA) } \\
\text { PROFESSOR - }\end{array}$ & $1999 / 2002$ & $\begin{array}{l}\text { PRESIDENTE } \\
\text { BANCO } \\
\text { FGV }\end{array}$ & $\begin{array}{l}\text { Pai: médico } \\
\text { Mãe: }\end{array}$ \\
\hline $\begin{array}{l}\text { MARIA } \\
\text { SILVIA } \\
\text { BASTOS } \\
\text { MARQUES }\end{array}$ & EBAP/FGV - 1987 & $2016 / 2017$ & PRESIDENTE & $\begin{array}{l}\text { Pai: médico } \\
\text { Mãe: Dir. } \\
\text { Conserv. }\end{array}$ \\
\hline
\end{tabular}

Fonte: Quadro elaborado pela autora.

ANEXO III - FOTOS

FAMÍLIA FRAGA:

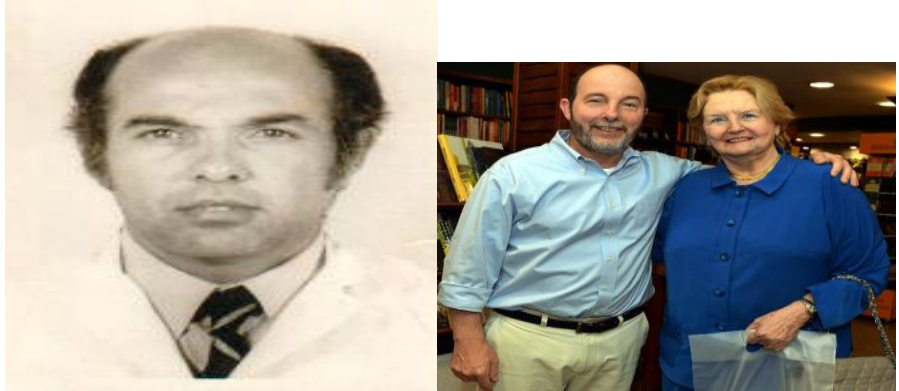

DR. SILVIO FRAGA ARMÍNIO FRAGA E SUA MÃE MARGARETH ANN BRESLAN 
Revista NEP - Núcleo de Estudos Paranaenses, Curitiba, v.5, n.1, jun. 2019

FAMÍLIA LOIOLA
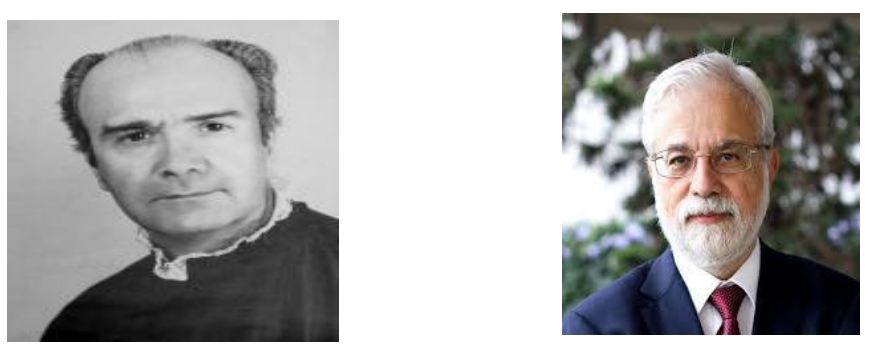

CLEUMAR DE BARROS LOIOLA

GUSTAVO JORGE LAOBOISSIÈRE LOIOLA
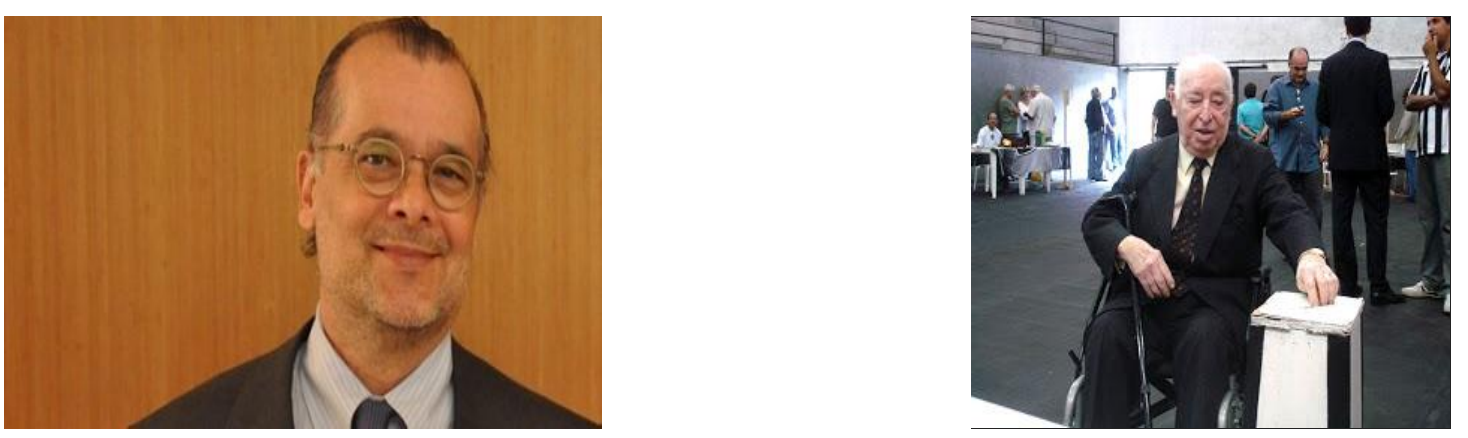

GUSTAVOHENRIQUE DE BARROSO FRANCO

GUILHERME ARINOS LIMA VERDE DE BARROSO FRANCO

MARIA SILVIA BASTOS MARQUES E FAMÍLIA

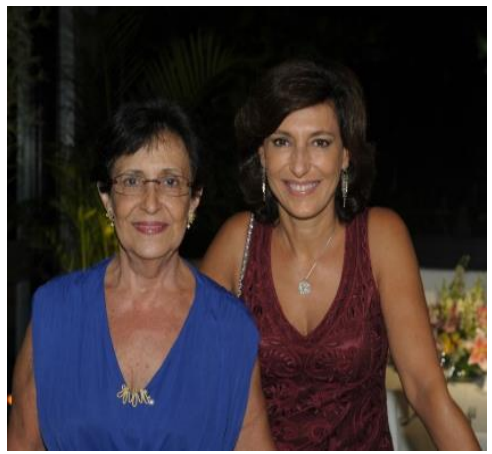

MARIA ALEXANDRINA

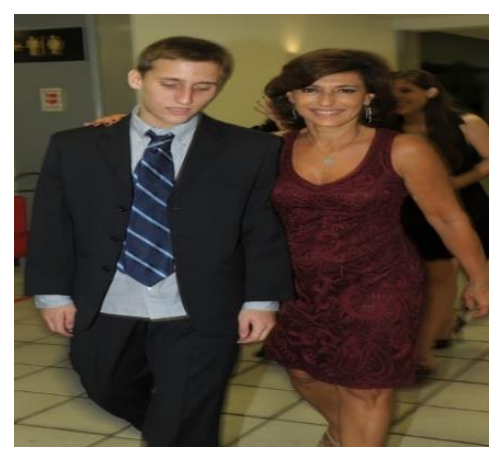

OTÁVIO WERLANG

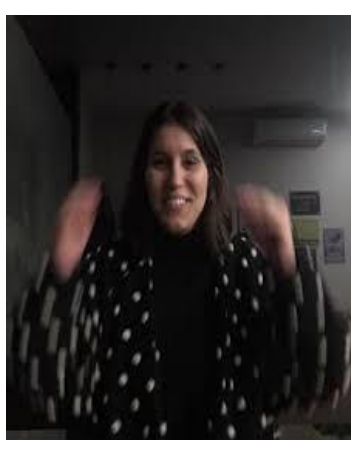

CATARINA WERLANG 
Revista NEP - Núcleo de Estudos Paranaenses, Curitiba, v.5, n.1, jun. 2019 Dossiê Partidos Políticos e Conexões Familiares

ISSN: 2447-5548

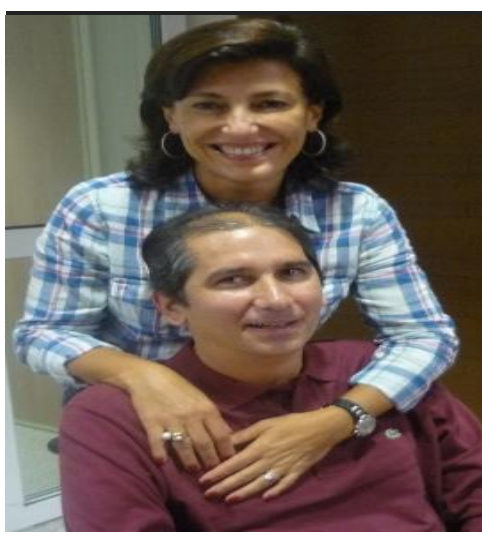

RODOLFO FERNANDES

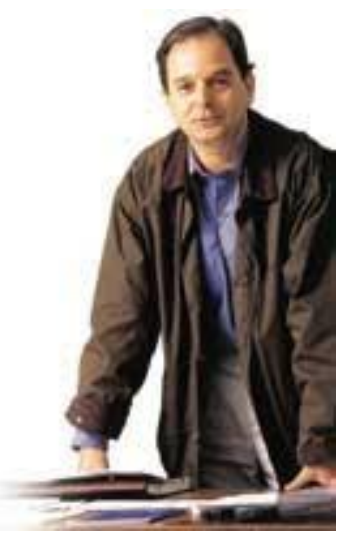

DAVID ZYLBERSZTAJN

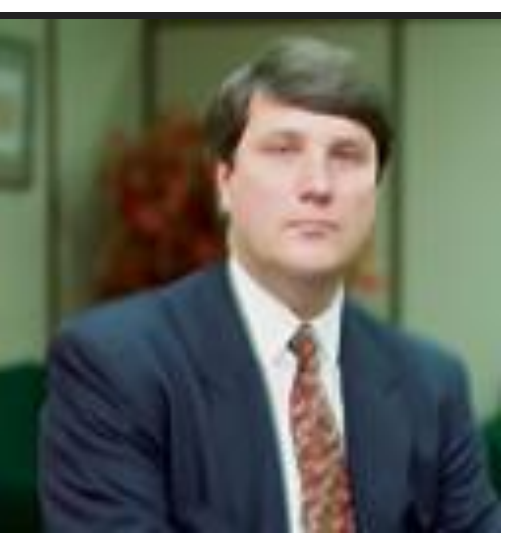

SÉRGIO WERLANG

Recebido em: 28 maio 2019.

Aceito em: 10 jun. 2019. 